\title{
Myxoma arising from the parotid gland
}

\author{
Seung Min Kim ${ }^{1}$, \\ Cheol Keun Kim ${ }^{1}$, \\ Soon Heum Kim ${ }^{1}$, \\ Myung Chul Lee', \\ Jee Nam Kim², \\ Hyun Gon Choi ${ }^{2}$, \\ Dong Hyeok Shin ${ }^{2}$, \\ Dong In Jo \\ ${ }^{1}$ Department of Plastic and \\ Reconstructive Surgery, Konkuk \\ University Chungju Hospital, Konkuk \\ University School of Medicine, Chungju; \\ ${ }^{2}$ Department of Plastic and \\ Reconstructive Surgery, Konkuk \\ University Medical Center, Konkuk \\ University School of Medicine, Seoul, \\ Korea
}

\begin{abstract}
Myxomas can be divided into two groups: those derived from the facial skeleton, and those derived from external skeletal soft tissue. Soft tissue myxomas of the head and neck are uncommon, with fewer than 50 cases reported. In any form and location, myxoma of parotid gland is rare. We report a case of myxoma arising from the left superficial lobe of the parotid gland with good longterm follow-up after superficial parotidectomy with tumor excision. A 49-year-old man was referred to our department of plastic and reconstructive surgery with a painless palpable mass that had persisted in the left mandible angle region for 2 years. Excision of the facial mass and superficial parotidectomy with facial nerve preservation were performed. The biopsy result was myxoma. Long-term follow-up for 22 months showed favorable results without evidence of recurrence but with temporary facial nerve weakness right after the surgery. Myxoma should be considered as a differential diagnosis when benign tumor of the parotid gland is being considered.
\end{abstract}

Keywords: Myxoma / Parotid gland / Salivary gland tumor / Soft tissue neoplasm

\section{INTRODUCTION}

Myxomas are benign connective tissue tumors of mesenchymal origin [1]. The term "myxoma" was first used by Virchow in 1871 to describe tumors that histologically resembled the mucinous tissue of the umbilical cord [2]. Myxomas can be divided into two groups: those derived from the facial skeleton, and those derived from external skeletal soft tissue. Most skeletal myxomas include the mandibular and maxillary, and myxomas of the skeletal muscle include the soft tissues of the limbs $[1,3]$. Soft tissue myxomas of the head and neck are uncommon, with fewer than 50 cases reported $[3,4]$. Soft tissue myxomas arise in somatic soft tissues mostly within the skeletal muscles, skin or subcutaneous tissues adjacent to large joints, the genitourinary

Correspondence: Dong In Jo

Department of Plastic and Reconstructive Surgery, Konkuk University Chungju Hospital, Konkuk University School of Medicine, 82 Gugwon-daero, Chungju 27376, Korea

E-mail: cozarmd@kku.ac.kr

Received February 27, 2019 / Revised April 4, 2019 / Accepted April 22, 2019 tract, the gastrointestinal tract, or in organs such as the liver and spleen $[1,5,6]$. In any form and location, myxoma of the parotid gland is rare. We report a case of myxoma arising from the left superficial lobe of the parotid gland with good longterm follow-up after superficial parotidectomy with tumor excision.

\section{CASE REPORT}

A 49-year-old man was referred to our department of plastic and reconstructive surgery with a painless palpable mass that had persisted in the left mandible angle region for 2 years (Fig. 1). He had no medical or surgical history. On physical examination, the skin was slightly elevated and a non-pliable mass was palpated. There was no tenderness or facial paralysis.

Ultrasonography revealed a well-defined hypoechoic solid mass measuring approximately $2.5 \times 2.5 \mathrm{~cm}$ in the left parotid gland (Fig. 2). Computed tomography (CT) also showed a nonenhancing low-density mass $2.4 \mathrm{~cm}$ in diameter in the inferior 


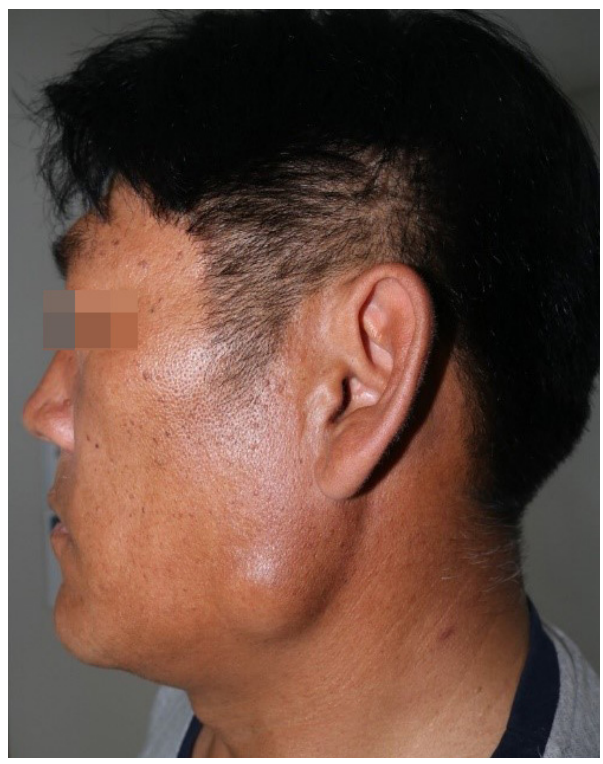

Fig. 1. Preoperative photograph of a 49-year-old male with a myxoma of the left mandibular angle region.

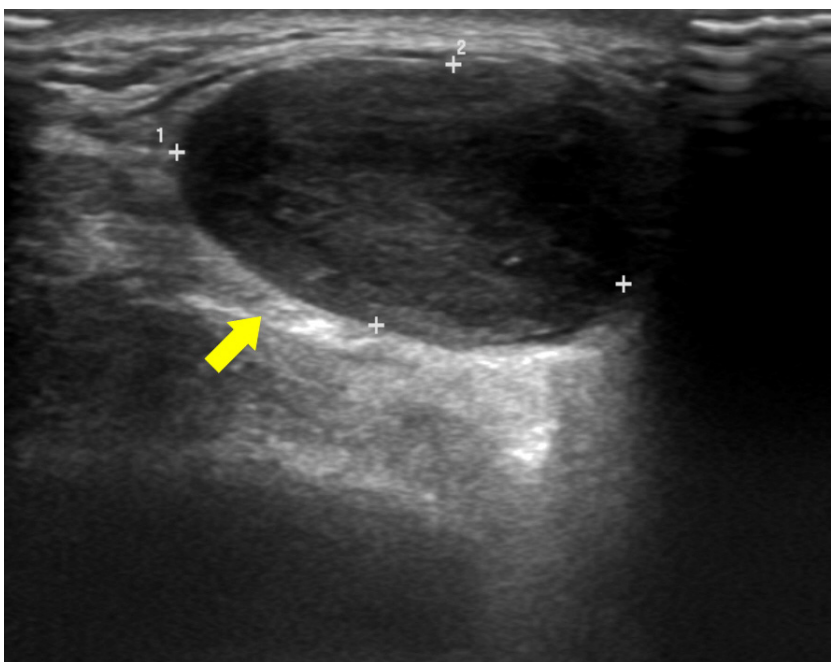

Fig. 2. Ultrasonography revealing a well-defined low-echoic lesion in the left parotid gland (yellow arrow).

portion of the left parotid gland, with no abnormal density inside the tumor (Fig. 3). There was no abnormality in the airway or thyroid gland. We performed fine needle aspiration cytology for differential diagnosis of malignant tumors such as mucoepidermoid carcinoma, adenoid cystic carcinoma, or pleomorphic adenoma. Fine needle biopsy revealed low cellularity, with ovoid or plump spindle-shaped incohesive cells in loose matrix material without a definite epithelial component.

For surgery, a "lazy S" incision was made in the preauricular area under general anesthesia. Excision of the facial mass and a superficial parotidectomy with facial nerve preservation were

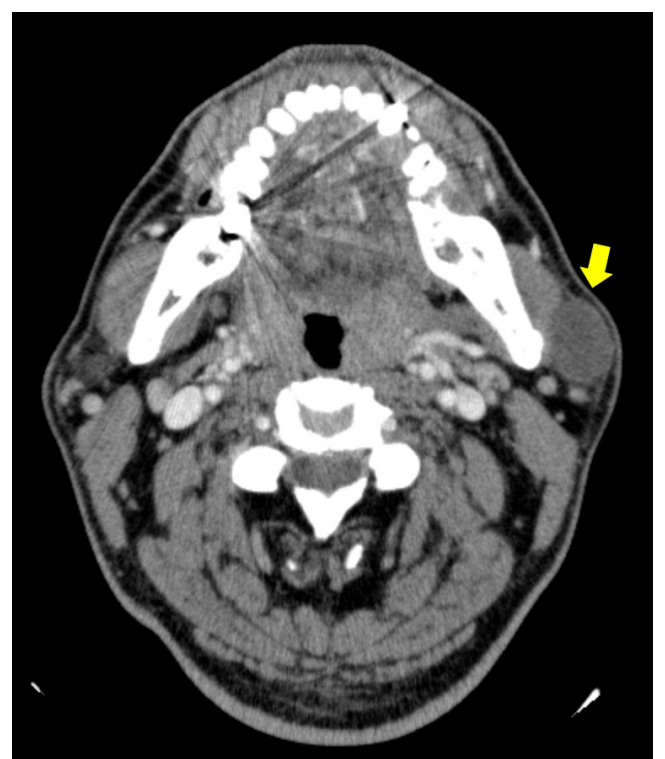

Fig. 3. An axial view of computed tomography scan disclosing a non-enhancing low-density mass $2.4 \mathrm{~cm}$ in diameter in the superficial lobe of the left parotid gland (yellow arrow).

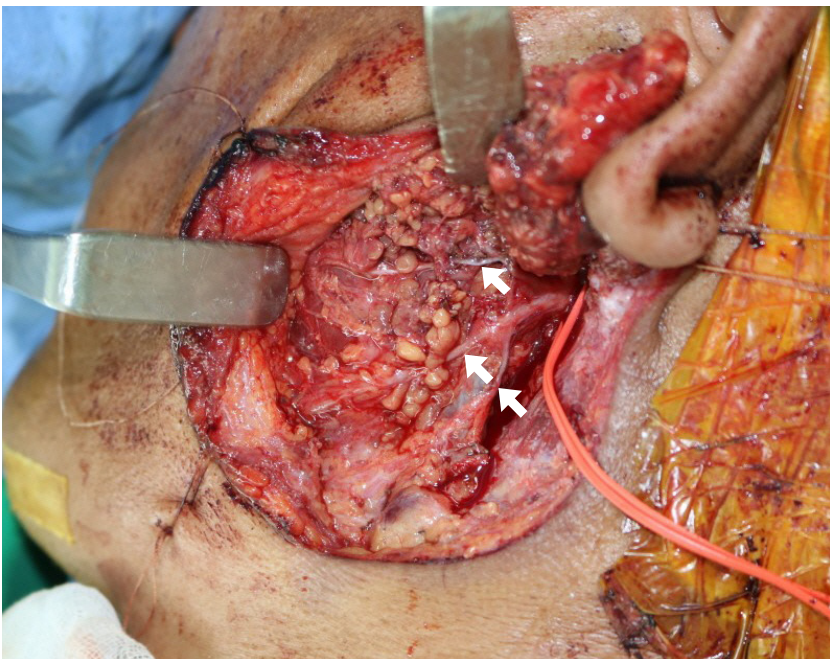

Fig. 4. Intraoperative photo showing complete excision of the tumor by superficial parotidectomy, with good preservation of the facial nerve (white arrows).

performed (Fig. 4).

The size of the resected parotid gland was approximately $4.5 \times 3.5 \times 2 \mathrm{~cm}$, including a myxoid gelatinous tumor with a clear border of $3.8 \times 3 \times 2 \mathrm{~cm}$ (Fig. 5). No bleeding or necrosis was observed on sectioning of the specimen.

Light microscopy revealed a well-demarcated tumor (Fig. 6A) characterized by hypocellularity, with bland spindle cells in a myxoid stroma and no evidence of mitosis, lipoblasts, cytologic atypia, or necrosis (Fig. 6B). The tumor was surrounded by fat and skeletal muscle. The adjacent salivary gland and lymph node showed no significant pathologic abnormality. 


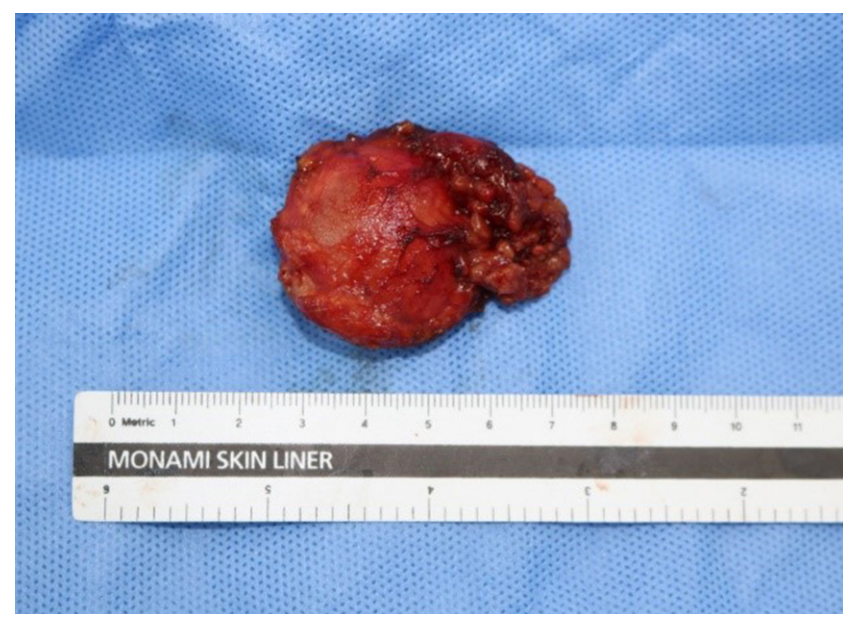

Fig. 5. Gross examination of the $3.8 \times 3 \times 2 \mathrm{~cm}$ myxoid gelatinous tumor showing the clearly circumscribed border.
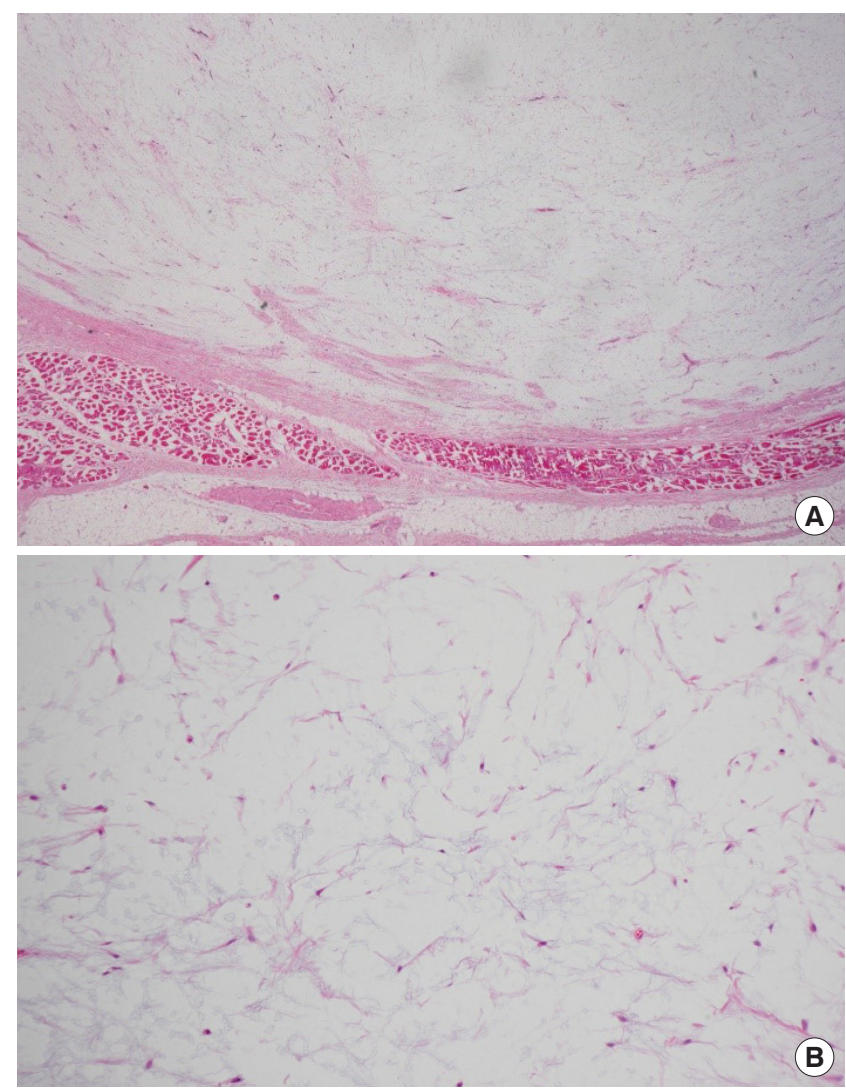

Fig. 6. Light microscopy. (A) Lower power field view showing a well-demarcated tumor surrounded by fat and skeletal muscle. The adjacent salivary gland and lymph node showed no significant pathologic abnormality $(\mathrm{H} \& \mathrm{E}, \times 12)$. (B) High power field view showing hypocellularity, with bland spindle cells in a myxoid stroma and no evidence of mitosis, lipoblasts, cytologic atypia, or necrosis $(\mathrm{H} \& \mathrm{E}, \times 100)$.

At the immediately postoperative physical examination, the left marginal mandibular branch of the facial nerve seemed temporarily weakened, but improved after 1 month. Over a fol-

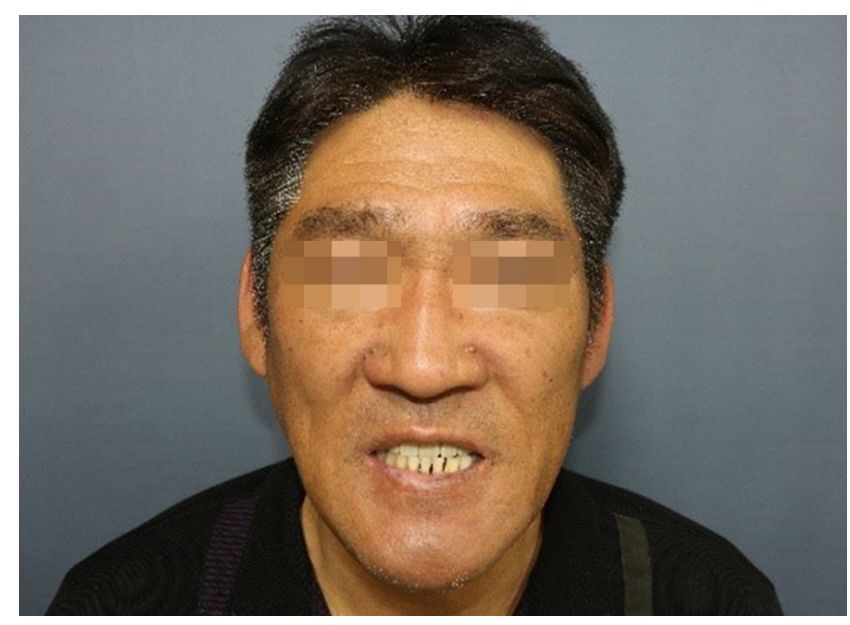

Fig. 7. Photograph of facial expressions was taken 22 months after surgery. The photo demonstrated that the movement of the nasolabial fold was fluent.

low-up period of 22 months after surgery there was no evidence of recurrence and no other complications were noted (Fig. 7).

\section{DISCUSSION}

The etiology of myxoma remains uncertain. The term myxoma was first introduced in 1871 by Rudolph Virchow (1821-1902), to describe tumors whose histological appearance was similar to the mucinous tissue of the umbilical cord [7]. In 1940, Ewing postulated that myxomas originate from the remnants of embryonal mesenchyme [8], and in 1948 Willis stated that they arise from degenerative changes in common fibromas [9]. Stout described the myxoma as a true mesenchymal neoplasm [10].

Myxomas of the head and neck region are rare. Canalis et al. [7] encountered only 10 such lesions over a 20 -year period at the UCLA Center for the Health Sciences. Two forms can be identified: facial skeleton "bone" derived, which were subdivided previously into true osteogenic myxoma and odontogenic myxoma; and "soft tissue" derived from perioral soft tissue, or the parotid gland, ear, or larynx [11,12]. Myxomas are most frequently reported in the heart, with the next most common site in the soft tissues of the thigh and shoulder [13].

The clinical features of soft tissue myxoma are not pathognomonic [14]. The usual clinical presentation of soft tissue myxomas is a painless, palpable mass. Growth tends to be slow and expansive, but myxomas may occasionally undergo a period of accelerated growth, leading to rapid enlargement [1]. They are not highly vascular and on radiographic studies usually appear radiolucent as a benign, expanding, circumscribed lesion. They are rarely multiple, and, to our knowledge, metastases have 
never been reported [3].

In $\mathrm{CT}$ and magnetic resonance (MR) images, the intrinsic characteristics of a soft-tissue myxoma resemble those of a cyst. This is a direct reflection of the high mucin and low collagen content in these lesions, which histology has shown to comprise a large water fraction $[15,16]$. The high-water content of myxomas accounts for their hypoechoic and low attenuation appearance on ultrasound and CT images respectively, their low signal intensity on T1-weighted MR images, and their markedly high signal intensity on T2-weighted MR images [16]. There are several distinguishing features of benign parotid neoplasms on MR images. Most are misdiagnosed as fibromas, lipomas, fibroepithelial polyps, oral focal mucinoses or tumors of the minor salivary glands [17]. Diagnosis can be confirmed only after histological examination of the lesion [14,17].

On gross examination, we found the lesion to be slimy, greyish, nodular, avascular in appearance, and only partly encapsulated. The tumor consistency varied slightly as a result of unevenly-distributed fibrosis [4].

On microscopic examination, diagnosis is made by identification of stellate cells and an irregular meshwork of reticular fibers in a matrix of mucoid material that contains hyaluronic acid [10].

Myxomas are benign lesions that do not metastasize but can be locally aggressive, with infiltration of surrounding tissues. The recommended treatment is surgical excision including a margin of normal-appearing tissue. Conservative treatment is indicated only for lesions close to vital structures, mainly in young patients [18]. Other types of treatment have been proposed, such as enucleation, removal, and radiotherapy, but these lead to high frequencies of recurrence and further wide surgical resection $[6,14,17]$. Recurrence is rare for soft tissue myxomas but myxomas of the facial bones have a recurrence rate of $25 \%$ that is related to incomplete excision [1]. In the present case no evidence of recurrence was found after a yearlong follow-up.

Differential diagnosis of a parotid mass is challenging because a wide range of possibilities exist, but a systematic, thoughtful, and ordered approach to imaging, laboratory studies, and pathologic analysis, coupled with a comprehensive history and physical examination, together allow the plastic surgeon to ascertain the correct diagnosis.

When patients with a unilateral painless parotid mass are referred to a plastic and reconstructive surgery department, we may consider benign neoplasm, malignancy, and lymphoma [19].

In conclusion, myxoma could be also considered as a differential diagnosis of the parotid gland benign tumor.

\section{NOTES}

\section{Conflict of interest}

No potential conflict of interest relevant to this article was reported.

\section{Ethical approval}

The study was approved by the Institutional Review Board of Konkuk University Hospital (IRB No. KUCH 2019-05-020) and performed in accordance with the principles of the Declaration of Helsinki. Written informed consent was obtained.

\section{Patient consent}

The patient provided written informed consent for the publication and the use of his images.

\section{ORCID}

Seung Min Kim

https://orcid.org/0000-0003-2310-2125

Cheol Keun Kim https://orcid.org/0000-0003-2126-9749

Soon Heum Kim https://orcid.org/0000-0001-9773-4753

Myung Chul Lee https://orcid.org/0000-0002-9721-0092

Jee Nam Kim https://orcid.org/0000-0002-7613-967X

Hyun Gon Choi https://orcid.org/0000-0002-2894-8720

Dong Hyeok Shin https://orcid.org/0000-0002-8450-4411

Dong In Jo https://orcid.org/0000-0002-3075-4482

\section{REFERENCES}

1. Batsakis JG. Myxomas of soft tissues and the facial skeleton. Ann Otol Rhinol Laryngol 1987;96:618-9.

2. Virchow R. Die Cellularpathologie in ihrer Begründung auf physiologische und pathologische Gewebelehre. Berlin: Hirschwald; 1871.

3. Quintal MC, Tabet JC, Oligny L, Russo P. Oral soft tissue myxoma: report of a case and review of the literature. J Otolaryngol 1994;23:42-5.

4. Pahor AL, Samant S. Retropharyngeal myxoma: a case report. J Laryngol Otol 1994;108:690-2.

5. Allen PW. Myxoma is not a single entity: a review of the concept of myxoma. Ann Diagn Pathol 2000;4:99-123.

6. Ramaraj P, Sah S. Myxoma of oral soft tissue. J Nepal Med Assoc $2003 ; 41: 266-70$.

7. Canalis RF, Smith GA, Konrad HR. Myxomas of the head and neck. Arch Otolaryngol 1976;102:300-5.

8. Ewing J. Neoplastic disease: a treatise on tumors. 4 th ed. Philadelphia: W.B Saunders; 1940.

9. Willis RA. Pathology of tumours. London: Mosby; 1948.

10. Stout AP. Myxoma, the tumor of primitive mesenchyme. Ann 
Surg 1948;127:706-19.

11. Regezi JA, Kerr DA, Courtney RM. Odontogenic tumors: analysis of 706 cases. J Oral Surg 1978;36:771-8.

12. Shafer WG, Hine MK, Levy BM, Rajendran R, Sivapathasundharam B. A textbook of oral pathology. 4th ed. Philadelphia: W.B Saunders; 1983.

13. Ghosh BC, Huvos AG, Gerold FP, Miller TR. Myxoma of the jaw bones. Cancer 1973;31:237-40.

14. Epivatianos A, Iordanidis S, Zaraboukas T. Myxoma of the oral soft tissues: report of a case and literature review. J Oral Maxillofac Surg 2007;65:317-20.

15. Hashimoto H, Tsuneyoshi M, Daimaru Y, Enjoji M, Shinohara N. Intramuscular myxoma: a clinicopathologic, immunohisto- chemical, and electron microscopic study. Cancer 1986;58:7407.

16. Murphey MD, McRae GA, Fanburg-Smith JC, Temple HT, Levine AM, Aboulafia AJ. Imaging of soft-tissue myxoma with emphasis on CT and MR and comparison of radiologic and pathologic findings. Radiology 2002;225:215-24.

17. James L, Shetty A, Jaypal N, Okade D. Oral soft tissue myxoma. J Indian Acad Oral Med Radiol 2012;24:152-4.

18. Andrews T, Kountakis SE, Maillard AA. Myxomas of the head and neck. Am J Otolaryngol 2000;21:184-9.

19. Kuan EC, Mallen-St Clair J, St John MA. Evaluation of parotid lesions. Otolaryngol Clin North Am 2016;49:313-25. 